\title{
ASPECTS OF ORGANIZATIONAL AMBIDEXTERITY
}

\author{
George PANAGOPOULOS
}

\begin{abstract}
The ability of an organization to be flexible and adaptive to change by exploring new opportunities while at the same time being effective and aligned with daily operations through exploiting current capabilities is defined as organizational ambidexterity. Achieving organizational ambidexterity is not trivial, and in this study at least three solutions are presented in order to support it (structural, temporal and contextual). Also, a review is conducted regarding the context of organizational ambidexterity in the framework of organizational learning, resource management, technology management and organizational behavior as well as about the factors affecting it.
\end{abstract}

Keywords: organizational ambidexterity; strategic management;organizational behaviour; organizational learning

\section{INTRODUCTION}

Research has revealed that successful organizations tend to balance the management of today's business demands while at the same time being adaptive to the future changes (Birkinshaw 2004). This ability is defined as organizational ambidexterity, and it was first proposed by Ducan in 1976 and extended by March in 1991, who introduced the two key terms exploration and exploitation. Organizational ambidexterity is a relatively complex concept that has been studied in various research domains including organizational learning, technology management, strategic management, knowledge management marketing e.t.c. as well as in different levels inside the organization or outside that in alliances.

Additionally, several antecedents, moderators and outcomes of organizational ambidexterity have been identified. This paper aims to sum up pieces of work that have been done on the nature of organizational ambidexterity. Contributions in the field of ambidexterity come from an interesting variety of research domains, and the initial debate has become more complex. Scholars have put forward different solutions, such as structural, temporal and contextual or combinations of them (cyclical, participational, harmonic and reciprocal ambidexterity). Also, suggestions have been made about the optimal mix of exploration and exploitation as well as about the trade-offs that there should be between them. In this study, organizational ambidexterity is viewed through the lenses of organizational learning, resource management, technology management and organizational behavior, among others. Also a review is made about the contexts affecting organizational ambidexterity.

\section{EXPLORATION AND EXPLOITATION}

\section{Exploration}

Exploration is connected to the seeking of new opportunities and the internalization and the application of new knowledge. The notion of exploration is subjected to relativity because it must be defined from the point of view of an organization or unit. Certain knowledge, technology or markets may be new to one organization, but unfamiliar to another. Consequently, one organization's exploration might be exploitation for another. There is also a dilemma on whether organizations which have developed their own knowledge are in better position to explore than those which have assessed the value of external knowledge and internalized it (Cohen and Levinthal 1990). Eventually, exploration aims to achieve product diversification, internationalization, variation in organizational forms or experimentation with new knowledge.

\section{Exploitation}

During exploitation, organizations develop routines, which further enhance their existing competences through repetition. Exploitation is related to organizational focus, experience and variation. Consequently, compared to exploration, exploitation is considered to be more certain, particularly in short term. Through exploitation, the current activities might become more efficient; nevertheless short-term enthusiasm might lead to a success trap (Leonard-Barton 1992) that will eventually guide the organization to compromise 
with the present situation. In cases like this, with too much focus on exploitation, organizations are likely to suffer from organizational inertia and become captured in a suboptimal equilibrium that makes adaptation difficult (Levinthal 1993).

\section{TRADE-OFF BETWEEN EXPLORATION AND EXPLOITATION}

A key question in organizational ambidexterity literature is how to balance exploration and exploitation. A range of solutions have been proposed to address this. Overall, it seems that some organizations have a tendency to emphasize on exploration whereas others on exploitation (Hamel et al. 1993), something that of course has to do with the level of aspiration within the organization (Cyert and March 1992). Scientists support that organizations have the tendency to focus on only one (Hamel et al 1993).

Nevertheless, balancing exploration and exploitation is essential as in most studies ambidexterity is strongly related to performance (Lavie et al 2010). Balancing exploration and exploitation is not easy, and the precise mix of exploration and exploitation that is optimal is hard to specify.

Some researchers believe that exploration should be kept at a minimal yet sufficient level with all remaining resources invested in exploitation (Levinthal 1993). Others consider that organizations should maintain equal proportions of exploration and exploitation activities (He \& Wong 2004). March (1991) considers that there is a continuous trade-off between these two groups of activities. The trade-off between exploration and exploitation is a decision between long term and short term, stability and adaptability, risk and return.

In any case, the choice between exploration and exploitation requires planning, execution of synchronized operations (Brown \& Eisenhardt 1997) and heterogeneous senior management teams (Boeker 1997). The exchange involved in organizational ambidexterity can be achieved naturally or systematically within different structures (Lavie 2010) or time periods.

\section{MODES OF EXPLORATION AND EXPLOITATION Organizational learning}

Jim March's (1991) study has drawn substantial interest in studying exploration and exploitation under the framework of organizational learning, knowledge management and innovation. Several approaches have been identified to balance the level of learning in organizations.

Exploitation, by some scholars, is considered as the use of current knowledge whereas exploration is about the pursuit of new knowledge. Others compare the merits of new knowledge development versus the refinement of existing knowledge (accumulation vs. adaptation) (Levinthal and March 1993). However, there seems to be a debate over whether exploration involves the development of things already known. From an alternative point of view, Gant and Baden-Fuller (2004) attribute the knowledge produced by some departments, such as R\&D, to exploration, and the knowledge produced by other units, such as marketing, to exploitation. Overall according to the model of (Fang et al. 2010) organizational learning may be related to the culture of each organization, the beliefs of individuals, and the external reality.

\section{Technology management}

One of the central research themes in technological innovation is the distinction between incremental and radical innovation (Abernathy \& Clark 1985). Incremental innovation involves relatively minor adaptations of existing products and business concepts. In contrast, radical innovation refers to fundamental changes leading to a switch from existing products and concepts to completely new ones. Alternatively, Tushman and Smith (2002) describe incremental innovations as those that serve the existing needs and radical innovations as those that serve the emerging opportunities. In studies, the problem of balancing exploration and exploitation is translated in choosing between the refinement of existing technology and the invention of new one (Wintern 1971). On the other hand, Brunner et al. (2009) state that the first time an organization experiments with a new technology, it enacts exploration but as the organization repeats its experiments, it develops explorative routines. As a result, exploration evolves into exploitation. Finally, it should be noted that in academic environments, there is a distinction between basic and applied research. From a managerial point of view, fusion of autonomy and support via 
disciplined project management has to be achieved, so as to deal with current projects, while at the same time, new product solutions have to be explored by means of low-cost experimentation.

\section{Resource management}

Compared to returns from exploitation, returns from exploration are less certain, more remote in time and more distant in locus of action (March 1991). In terms of trade-off, exploration and exploitation compete for the same resources, and the efficiency of this trade off depends on the effectiveness of the senior management team (Helfat \& Peteraf 2009). As a result, often when exploitation generates a reasonable return on investment, the value of exploration is undermined.

Nevertheless, in order to be viable, organizations must invest in the discovery of new knowledge and be alerted about market opportunities so as to secure future economic gains, considering that exploitation can produce income that can then be invested in future exploration (Lavie 2010). On the other hand, organizations that explore to the exclusion of exploitation suffer the costs of experimentation without gaining the benefits associated with exploiting extant opportunities (March 1991). Indeed, from a financial point of view, Auh and Menguc (2005) demonstrate that exploration contributes to long-term performance captured by market share growth and sales growth. However, short-term performance that is related to return on assets is associated with exploitation.

\section{Organizational behavior}

Many scholars have suggested that long-term success requires organizational balance between continuity and change (Brown and Eisenhardt 1997). Meyer and Stensaker (2006) relate ambidexterity to an organization's capacity to balance the need to implement change with that of maintaining its daily operations. Thus, whereas exploitation is associated with activities such as "refinement, efficiency, selection and implementation", exploration refers to notions such as "search, variation, experimentation and discovery" (Lavie 2010). Theories are commonly built on the belief that too many (or too radical) change options may lead to organizational chaos if continuity is not taken into account, whereas the opposite could lead to inertia (Huy 2002). In the process of balancing exploration and exploitation, in this case the beliefs held by individuals in an organization might be neutral or different. However, these are adapted with socialization, and then organizations become homogeneous. In terms of structure, Burns and Stalker (1976) argue that mechanistic structures that rely on standardization, centralization and hierarchy support efficiency whereas organizational structures with their level of centralization support and flexibility.

\section{BALANCING EXPLORATION AND EXPLOITATION}

Balancing exploration and exploitation is not easy. At least three options have been proposed to solve this problem: 


\section{Fig 1. Solutions For Balancing Exploration And Exploitation}

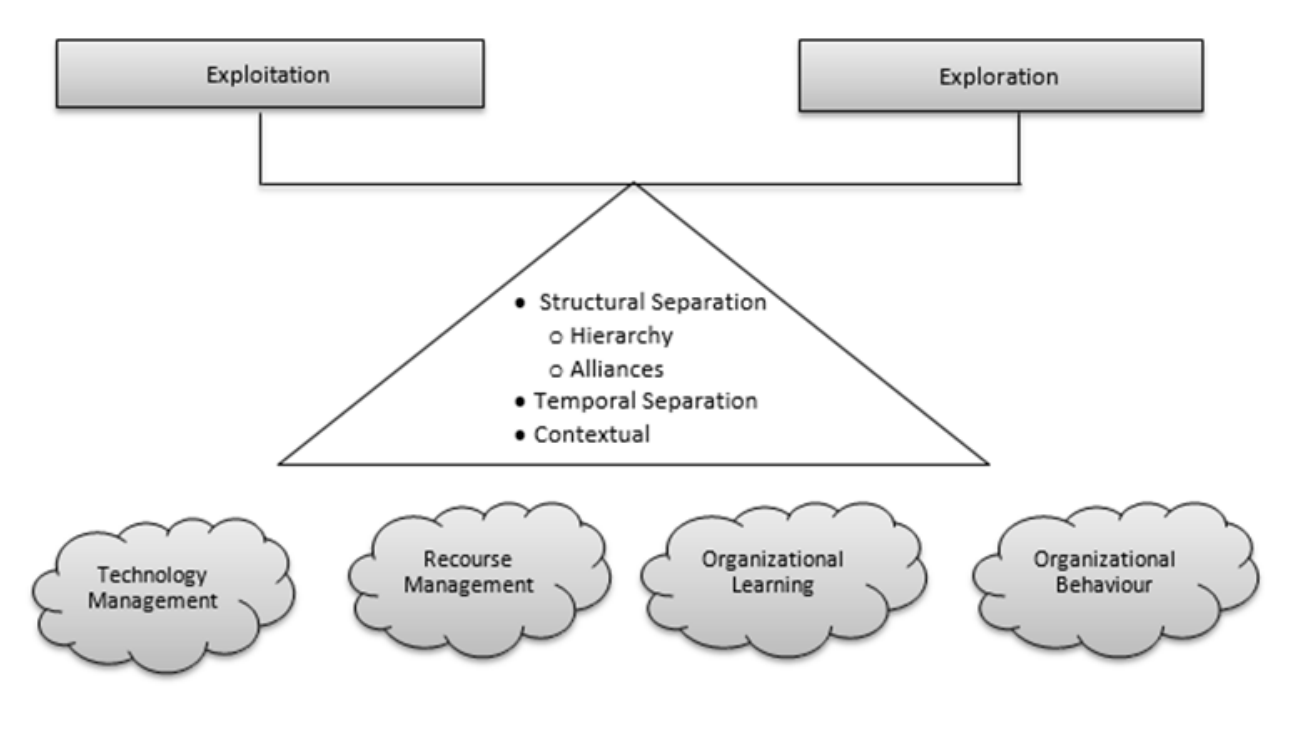

\section{Contextual ambidexterity}

In contextual ambidexterity, exploration and exploitation naturally balance with each other. Particular individuals maintain an equilibrium between creativity, attention to detail and quality performance in a way that innovative performance does not necessarily undermine quality and efficiency (Miron 2004). Gibson and Birkinshaw (2004) relate the ability to balance exploratory and exploitative activities to an organizational context characterized by an interaction of stretch, discipline, support and trust.

\section{Organizational separation}

In structurally ambidextrous organizations, highly differentiated units exist that conduct either exploitation or exploration with internal consistency in tasks and culture (Tushman et al. 1996). In structurally ambidextrous organizations, exploitative units (such as marketing departments) are larger and more centralized, with tight cultures that focus on maximizing efficiency and control through process management (Benner 2003). In turn, exploratory units (i.e., R\&D departments) are smaller, decentralized and more flexible so as to generate innovation through experimentation.

By loosely integrating their exploratory and exploitative units, organizations simultaneously perform both activities and balance them within their boundaries through active integration of senior management teams (Jansen et al. 2009). However, it is unclear to what extent senior management can manage contradictions that emerge later at the operational level.

\section{Working in alliances}

A more extreme form of organizational separation involves spin-outs and corporate venture capital investments whereby exploration takes place in external autonomous units (Ahuja et al 2008). For example in this case exploration might be conducted by separate enterprises or universities with the support of star scientists (Lavie et al 2009).

\section{Working in different levels}

Naturally, inside organizations, power is distributed across different functions or units. Frequently, topdown knowledge inflows from persons at higher hierarchical levels are positively related to exploration. Contrarily, horizontal and bottom-up knowledge inflows from peers and persons at lower hierarchical levels are related to exploitation (Lavie 2010). In this case, the emphasis on exploration versus exploitation shifts across organizational units positioned across different hierarchical levels (Brunner et al 2009). 


\section{Temporal separation}

Temporal separation involves cycles of exploration and exploitation during which an organization focuses only on one dominant activity and later shifts to the other. Temporal separation at organizational level assumes that organizations proactively manage the transition between exploratory and exploitative efforts (Siggelkow et al 2003) so as to evade conflicting pressures of simultaneous exploration and exploitation (Lavie et al 2006). The temporal shifts from one activity to another are not easy, given that conflicting pressures for exploration and exploitation still operate at time transitions. Subsequent transitions might be costly to implement hence temporal separation entails developing efficient procedures for managing transitions from one mode to the other (Brown and Eisenhardt 1997).

\section{COMPLEX SOLUTIONS FOR BALANCING EXPLORATION AND EXPLOITATION \\ Cyclical ambidexterity}

In cyclical ambidexterity, organizations engage in long periods of exploitation (ie, relative stability), interupted by sporadic episodes of exploration or change (punctuated equilibrium) (Gersik 1991). A strong technological orientation is the most silent determinant of cyclical ambidexterity. Based on available research, cyclical ambidexterity is most strongly associated with innovative outcomes, notably product innovation. It seems that technologically oriented business units that engage in successive rounds of exploration and exploitation are best equipped to pursue product innovations (Tushman et al 1996) as the business units are not caught in contingency (over-exploiting) and failure traps (over-exploring) (Siggelkow 2003).

\section{Reciprocal ambidexterity}

Reciprocal ambidexterity involving the sequential pursuit of exploration and exploitation across units has received the least attention from researchers. In this case, the outputs of exploration from unit A become the inputs for exploration by unit B, and the outputs of unit B cycle back to become the inputs of unit A (Thompson 1967). Moreover, unlike cyclical ambidexterity, which involves managers simply passing the baton at some point in time, this type requires relationships characterized by ongoing information exchange, collaborative problem solving, joint decision making and resource flows between the managers of different units.

\section{Participational ambidexterity}

From this point of view, pursuing ambidexterity requires the establishment of structurally independent units, each having its own strategies, structures, cultures and incentive systems (Banner and Tushman 2003). Essentially, each unit houses its own distinct management team, organizational structure, culture, control systems and incentive structures (Benner and Tushman 2003). Each one innovates separately, and afterwards the joint work is done under the guidance of senior management. Shared vision among senior managers was positively associated with ambidexterity.

\section{Harmonic ambidexterity}

In harmonic ambidexterity, an optimal balance between exploration and exploitation is sustained within a single unit which involves building a set of processes that enable and encourage individuals to make their own judgments about how to divide their time between the conflicting demands of exploration and exploitation (Gibson and Birkinshaw 2004).

The present study aims to undertake a review of the contexts affecting organizational ambidexterity in at least four different ways. From an organizational point of view, the culture in an organization, the management and the joint decision making might have impact on the mix of organizational ambidexterity. From a learning perspective, absorptive capacity and psychological safety are studied. In terms of structure, organizational age and size can play a significant role in the type of organizational ambidexterity achieved. Finally, in the external environment, dynamism, market orientation and competitive intensity might determine the levels of exploration or exploitation needed for survival.

\section{FACTORS AFFECTING ORGANIZATIONAL AMBIDEXTERITY}

Scholars have identified several contexts affecting organizational ambidexterity in at least four different ways. From an organizational point of view, the culture in an organization, the management and the joint 
decision making might have impact on the mix of organizational ambidexterity. From a learning perspective, absorptive capacity and psychological safety are studied. In terms of structure, organizational age and size can play a significant role in the type of organizational ambidexterity achieved. In the external environment, dynamism, market orientation and competitive intensity might determine the levels of exploration or exploitation needed for survival.

\section{Organizational factors}

\section{Management}

As leaders in organizations, managers are regarded to play an important role in fostering ambidexterity. Tushman and O' Reilly (1997) state that ambidexterity is facilitated by the management team's internal processes. The choices of an organization's management may influence its tendency to explore versus to exploit. Risk-averse managers are engaged in exploitation, since the benefits in this case are more proximate, certain and intermediate, thus generally preferable by more hesitant decision makers (Lewin and Carroll 1999). In turn, risk-prone managers may be motivated by either survival or performance aspirations (March \& Shapira 1992). In any case, the optimal management of the trade-off between exploration and exploitation required for survival may be different for each organization, and it is dependent on its strategy.

\section{Participation in decision making}

Participation in decision making supports ambidexterity by benefiting both exploration and exploitation processes. This practice is important for exploration as it provides an activation trigger for the generation of new ideas (Cohen, Wesley and Levinthal 1990). On the other hand, through joint decision making, the new ideas proposed are adjusted and viewed from a more realistic basis. In this process, it is very important to involve leaders who can explain the need for change to the team and increase commitment to explore new ways of doing things (Raisch \& Birkinshaw 2008).

\section{Organizational identity}

Exploratory and exploitative activities are guided by the organizational goals and dominant logics in each organization (Miles \& Snow 1978; Tripsas 2009). Organizational culture, experiences, beliefs and values that impact the behavior of organizational members might affect their tendency towards exploration or exploitation. Sorensen (2002) has demonstrated that organizations with strong cultures whose members share a set of strongly held norms tend to stay within the realm of what is already known and engage more in exploitation whereas open cultures with appetite for change usually benefit from exploration.

\section{Learning factors Absorptive capacity}

An organization's ability to explore is associated with its absorptive capacity, meaning its ability to assess the value of external knowledge, internalize it and apply it (Cohen \& Levinthal 1990). Absorptive capacity enhances the interaction of an organization with the external environment (Rosenkopf \& Renkar 2001) and improves the learning that takes place within or between its sub-units. Thus absorptive capacity enables an organization to operate proactively and explore emerging technologies and market opportunities (Rothaermel \& Alexandre 2009).

\section{Psychological safety}

Psychological safety is related to the extent to which the members of an organization feel psychologically safe to take interpersonal risks that might cause mistakes which will be used to undermine efforts for exploration (Edmondson 1999). Often it is hard for employees to share or implement new ideas due to uncertainty about their job (Bijlsma 2001). Exploration is risky, and low psychological safety can create fear of being punished for its anticipated outcomes. Also, exploration is difficult in environments perceived as unsafe for risk taking (ie. in the financial sector). 


\section{Structural factors \\ Age of organization}

Young ventures tend to invest in exploration as they do not have yet established organizational roles and structuring relations. Also they explore in order to identify new opportunities that will differentiate them from the competition. However, they do also need to engage in exploitation as they usually subject to liabilities that make them more susceptible to failure (Stinchcombe 1965). Liabilities of newness arise from the lack of specific resources, the limited customer base and the investments needed. On the other hand, older organizations encounter difficulties in keeping up with technological advancements, as they become dependent on established routines and skills which facilitate inertial pressures, frequently relying on existing knowledge and experiences to respond in a consistent and accountable manner to environmental challenges. Therefore, they tend to engage more in exploitation than exploration (Lavie et al 2010).

\section{Size of organization}

Research has shown that organizational inertia increases with size, and as a result, innovation and change are becoming more and more difficult. Thus Rothaermel and Deeds (2004) affirm that small size is positively related to exploitation. Nevertheless, other researchers suggest that bigger organizations are in a better position to explore as they are able to take advantage more easily of their internal resources that can support exploration (Sidhu 2004).

\section{Market Factors Environmental dynamism}

Environmental dynamism is defined as the extent of unpredictable change in an organization's environment (Dess \& Beard 1984). In dynamic environments, products in the market become easily obsolete, regulations frequently change and organizations need to engage more in exploration. Generally, environmental uncertainty increases the rate of innovation required for survival and hence an organization's investment in exploration. Exploitation has better chances of survival in stable environments, whereas turbulent environments favor organizations that can promptly take advantage of emerging opportunities and abandon expiring certainties (Hannman \& Freeman 1984). Alternatively, organizations that wish to deal with market uncertainty may choose to seek external resources from similar or familiar partners (Beckman et al. 2004).

\section{Market orientation}

Market orientation refers to the ability of an organization to place highest priority on customer satisfaction by taking into consideration the interests of other stakeholders as well. Market orientation is reflected by the three dimensions of customer orientation, competitor orientation and inter-functional coordination (Kohli \& Jaworski 1990). Market orientation guides managerial decisions towards simultaneously allocating resources to exploit existing product innovation competences as well as to develop new innovation capabilities (Atuahene-Gima 2005). Organizations become more efficient as they leverage accumulated experience and established ties to vendors, customers and stakeholders (Penrose 1959).

\section{COMPETITIVE INTENSITY}

In general, competitive intensity increases with the number of competitors and results in lower prices and tighter margins (Lavie et al. 2006). Under such conditions, the improvement of existing products or services becomes essential. Nevertheless, after some point, exploration becomes insufficient for withstanding the competition, and exploration is needed in order to drive change and reveal new competitive advantages. Incentives to exploit dominate when competitive tension is dumped and organizations generate reasonable return on investment by leveraging existing products, services and technologies without incurring exploration risks.

\section{CONCLUSIONS}

Organizational ambidexterity is a notion which has been studied for several years now through the lenses of various disciplines, including strategic management, organizational behavior, marketing and others. It has been characterized by several scholars as a very significant context contributing substantially to 
performance (Lavie 2010). Nevertheless achieving it is not easy as frequently the forces put by exploration and exploitation are competing with each other. In order to deal with this situation several organizational solutions have been suggested however there seem to be opportunities for further research in certain more complex cases. Indicatively some areas that could be studied more would have been organizational ambidexterity in alliances and organizational ambidexterity in different hierarchy levels. 


\section{REFERENCES}

Abernathy, W. J., \& Clark, K. B. (1985). Innovation: Mapping the winds of creative destruction. Research policy, 14(1), 3-22.

Ahuja, G., Lampert, C. M., \& Tandon, V. (2008). 1 moving beyond Schumpeter: management research on the determinants of technological innovation. The Academy of Management Annals, 2(1), 1-98.

Atuahene-Gima, K. (2005). Resolving the capability_rigidity paradox in new product innovation. Journal of marketing, 69(4), 61-83.

Auh, S., \& Menguc, B. (2005). Balancing exploration and exploitation: The moderating role of competitive intensity. Journal of Business Research, 58(12), 1652-1661.

doi:10.1016/j.jbusres.2004.11.007

Beckman, C. M., Haunschild, P. R., \& Phillips, D. J. (2004). Friends or strangers? Firm-specific uncertainty, market uncertainty, and network partner selection. Organization science, 15(3), 259-275.

Benner, M. J., \& Tushman, M. L. (2003). Exploitation, exploration, and process management: The productivity dilemma revisited. Academy of management review, 28(2), 238-256.

Boeker, W. (1997). Strategic Change: The Influence Of Managerial Characteristics And Organizational Growth. Academy of Management Journal, 40(1), 152-170.

Brown, S. L., \& Eisenhardt, K. M. (1997). The art of continuous change: Linking complexity theory and time-paced evolution in relentlessly shifting organizations. Administrative science quarterly, 1-34.

Brunner, D. J., Staats, B. R., Tushman, M. L., \& Upton, D. N. (2009). Wellsprings of creation: Perturbation and the paradox of the highly disciplined organizations. Cambridge, MA: Harvard Business School.

Burns, T. E., \& Stalker, G. M. (1961). The management of innovation. University of Illinois at UrbanaChampaign's Academy for Entrepreneurial Leadership Historical Research Reference in Entrepreneurship.

Cao Qing, Eric Gedajlovic, and Hongping Zhang.(2009). Unpacking Organizational Ambidexterity: Dimensions, Contingencies, and Synergistic Effects. Organization Science 20.4 , 781-796.

Cohen, W. M., \& Levinthal, D. A. (1990). Absorptive capacity: A new perspective on learning and innovation. Administrative science quarterly, 128-152.

Cyert, R. M., \& March, J. G. (1963). A behavioral theory of the firm. Englewood Cliffs, NJ: PrenticeHall.

Dess, G. G., \& Beard, D. W. (1984). Dimensions of organizational task environments. Administrative science quarterly, 52-73.

Duncan B. (1976) .The ambidextrous organization: Designing dual structures for innovation. The Management of Organization 1, 167-188

Edmondson, A. (1999). Psychological safety and learning behavior in work teams. Administrative science quarterly, 44(2), 350-383.

Frans A. J. Van Den Bosch, Volberda, H. W., \& Boer, M. D. (1999). Coevolution of Firm Absorptive Capacity and Knowledge Environment: Organizational Forms and Combinative Capabilities. Organization Science, 10(5), 551-568.

Gersick, C. J. (1991). Revolutionary change theories: A multilevel exploration of the punctuated equilibrium paradigm. Academy of management review, 16(1), 10-36.

Gibson, C. B., \& Birkinshaw, J. (2004). The antecedents, consequences, and mediating role of organizational ambidexterity. Academy of management Journal, 47(2), 209-226.

Grant, R. M., \& Baden-Fuller, C. (2004). A Knowledge Accessing Theory of Strategic Alliances. Journal of Management Studies J Management Studs, 41(1), 61-84. doi:10.1111/j.1467-6486.2004.00421.x 
Hamel, G., \& Prahalad, C. K. (n.d.). Strategy as stretch and leverage.

Hannan, M. T., \& Freeman, J. (1984). Structural inertia and organizational change. American sociological review, 149-164.

He, Z., \& Wong, P. (2004). Exploration vs. Exploitation: An Empirical Test of the Ambidexterity Hypothesis. Organization Science, 15(4), 481-494. doi:10.1287/orsc.1040.0078

Helfat, C. E., \& Peteraf, M. A. (2009). Understanding dynamic capabilities: Progress along a developmental path. Strategic Organization, 7(1), 91-102. doi:10.1177/1476127008100133

Huy, Q. N. (2002). Emotional balancing of organizational continuity and radical change: The contribution of middle managers. Administrative science quarterly, 47(1), 31-69.

Jansen Justin, Zeki Simsek, and Qing Cao. (2012) Ambidexterity and performance in multiunit contexts: cross-level moderating effects of structural and resource attributes. Strat. Mgmt, 1286- 1303

Jansen, J. J., Tempelaar, M. P., Van den Bosch, F. A., \& Volberda, H. W. (2009). Structural differentiation and ambidexterity: The mediating role of integration mechanisms. Organization Science, 20(4), 797-811.

Kohli, A. K., \& Jaworski, B. J. (1990). Market orientation: the construct, research propositions, and managerial implications. The Journal of Marketing, 1-18.

Lant, T. K., \& Mezias, S. J. (1992). An Organizational Learning Model of Convergence and Reorientation. Organization Science, 3(1), 47-71. doi:10.1287/orsc.3.1.47

Lavie Dovev, Uriel Stettner, and Michael Tushman. (2010). Exploration and Exploitation Within and Across Organizations. The Academy of Management Annals 4, 109-155

Lavie, D. (2006). Capability reconfiguration: An analysis of incumbent responses to technological change. Academy of management review, 31(1), 153-174.

Lavie, D., Stettner, U., \& Tushman, M. L. (2010). Exploration and exploitation within and across organizations. The Academy of Management Annals, 4(1), 109-155.

Lavie, Dovev, and Lori Rosenkopf. (2006) . Balancing exploration and exploitation in alliance formation. Academy of Management Journal 49.4, 797-818.

Leonard-Barton, D. (1992). Core capabilities and core rigidities: A paradox in managing new product development. Strat. Mgmt. J. Strategic Management Journal, 111-125

Levinthal, D. A., \& March, J. G. (1993). The myopia of learning. Strat. Mgmt. J. Strategic Management Journal, 95-112

Lewin, A. Y., Long, C. P., \& Carroll, T. N. (1999). The coevolution of new organizational forms. Organization Science, 10: 535-550.

Lubatkin, M. H., Simsek, Z., Ling, Y., \& Veiga, J. F. (2006). Ambidexterity and performance in small-to medium-sized firms: The pivotal role of top management team behavioral integration. Journal of management, 32(5), 646-672.

March, J. G. (1991). Exploration and exploitation in organizational learning. Organization science, 2(1), 71-87.

March, J.G., \& Shapira, Z. (1992). Variable risk preferences and the focus of attention. Psychological Review, 99(1), 172-183.

Meyer, C. B., \& Stensaker, I. G. (2006). Developing capacity for change. Journal of Change Management, 6(2), 217-231.

Miles, R.E., \& Snow, C.C. (1978) Organizational strategy, structure and process. New York: McGrawHill.

Miron, E., Erez, M., \& Naveh, E. (2004). Do personal characteristics and cultural values that promote innovation, quality, and efficiency compete or complement each other?. Journal of organizational behavior, 25(2), 175-199. 
Penrose, E. T. (1995). The Theory of the Growth of the Firm. Oxford University Press, USA.

Porter, Michael E. Competitive Strategy: Techniques for Analyzing Industries and Competitors. New York: Free, 1980. Print.

Raisch Sebastian, and Julian Birkinshaw.(2008). Organizational Ambidexterity: Antecedents, Outcomes, and Moderators. Journal of Management,: 375-409

Rosenkopf, L., A. Nerkar. (2001). Beyond local search: Boundary- spanning, exploration, and impact in the optical disk industry. Strategic Management J, 22 287-306.

Rothaermel Frank, and Maria Alexandre. (2009) Ambidexterity in Technology Sourcing: The Moderating Role of Absorptive Capacity. Organization Science 20.4, 759-780

Rothaermel, F. T., \& Deeds, D. L. (2004). Exploration and exploitation alliances in biotechnology: A system of new product development. Strategic management journal, 25(3), 201-221.

Sidhu, J. S., Volberda, H. W., \& Commandeur, H. R. (2004). Exploring exploration orientation and its determinants: Some empirical evidence*. Journal of Management Studies, 41(6), 913-932.

Siggelkow, N. (2001). Change in the presence of fit: The rise, the fall, and the renaissance of Liz Claiborne. Academy of Management Journal, 44(4), 838-857.

Simsek, Z., Heavey, C., Veiga, J. F., \& Souder, D. (2009). A typology for aligning organizational ambidexterity's conceptualizations, antecedents, and outcomes. Journal of Management Studies, 46(5), 864-894.

Sorensen, J.B. (2002). The strength of corporate culture and the reliability of firm per- formance. Administrative Science Quarterly, 47(1), 70-91.

Stettner, U., \& Lavie, D. (2011). The Performance Effects of Balancing Exploration and Exploitation Within and Across Governance Modes. Academy of Management,

Stinchcombe, A. L., \& March, J. G. (1965). Social structure and organizations. Advances in strategic management, 17, 229-259.

Thompson, J. D. (1967). Organizations in action: Social science bases of administrative theory. Transaction publishers.

Tripsas (2009), M. Technology, identity, and inertia through the lens of "the digital photography company." Organization Science, 441-460.

Tushman, M. L., \& O’Reilly, C. A. (1997) Winning through innovation: A practical guide to managing organizational change and renewal, Cambridge, MA: Harvard Business School Press

Tushman, M. L., \& O'Reilly, C. A. (1997). Ambidextrous organizations: Managing evolutionary and revolutionary change. Quality Control and Applied Statistics, 42, 215-218. 